steel frame. All piping work, oven vacuum dehydrat. ing, charging and testing of the system are under strict factory conditions. The units are usually placed in a stock room at the rear of a shop, in the basement, or on a balcony, and are connected to the occupied space by means of a suitable duct system.

\section{Radio Traffic Control in America}

A NOVEx plan to bring traffic signals into cars in the form of distinctive tones corresponding to the 'stop' and 'go' lights, may in time make a carradio a legal requirement on every car in the United States. In its present form, this traffic-control system uses the existing car radio tuned to $550 \mathrm{kc}$., thus making the system immediately available for the six million cars now equipped with auto-radios, though eventually a special small set would be employed with fixed tuning to the highway safetysignal frequency. By the use of this signal, the driver, instead of letting his attention wander from the roadway in his search for traffic signals in unfamiliar territory, would hear a pleasant low tone as long as the lights were green. When red comes $o n$, in all cars in that section of the roadway an interrupted high note would be heard similar to that caused by a crossing signal.

Recorded messages can be used for continuous repetition of a message. The small highway transmitting unit, which may be mounted on a telephone pole or a traffic light stanchion, makes use of a magnetic tape sound-recording device. A distinctive sign placed on the street in advance of a given radio zone attracts the attention of motorists to the radio system which they are approaching and gives them the frequency to which to tune their set. By means of this device, traffic can be diverted to a secondary thoroughfare from crowded highways, preventing jams before cars have a chance to pile up, and drivers can be warned of speed limits or of emergency in case of fire or accident.

\section{Data of Seismology}

From the Government of India Meteorological Department comes the valuable Seismological Bulletin for October-December 1939. Interpretations of readings of the seismograms from Agra, Bombay, Calcutta, Colombo, Dehra Dun, Hyderabad, and Kodaikanal are given. Furthermore, J. H. Sil at Poona has collected 58 non-instrumental reports of shocks, five being in October, eight in December, and the remainder in November. Three of the reports noted earthquakes reaching intensity 9 on the Rossi-Forel scale. By far the strongest shock was on November 21, 1939, at about 11 h. 1 m. G.M.T. At Gilgit stones fell from the mountains, and dust spread all over the valley. At Drosh intensity 9 was reached, whilst at Srinagar the walls of the observatory and other buildings cracked.

The Seismological Bulletin of the Riverview College Observatory (New South Wales) for July, August and September 1940, has also been received. The Observatory is equipped with three Wiechert and two Mainka seismographs, the interpretation of the seismograms from which are given. The shock of July 31, 1940, was felt at Cape Nelson, Papua. The earthquake of September 12, 1940, was felt at Rabaul, New Britain, also in the Kokopo district, and at Wide Bay, Pondo, Namatanai and Buka. To this earthquake there were several strong aftershocks. The shock of September 21, 1940, was felt at Queanbeyan, New South Wales, but did no damage. Some deep-focus shocks were recorded, and some slight shocks lacked interpretation, since the area is to some extent troubled with microseisms.

\section{Earthquakes near America}

The United States Coast and Geodetic Survey, in co-operation with Science Service and the Jesuit Seismological Association, has made a preliminary determination of the epicentres of the earthquakes of February 9 and February 11. The former had its initial time $9 \mathrm{~h} .44 \cdot \mathrm{lm}$. G.M.T., and on a basis of reports from 22 seismographic stations the epicentre appeared to be at latitude $40 \cdot 7^{\circ} \mathrm{N}$., longitude $125.4^{\circ} \mathrm{W}$. This is in the Pacific Ocean just off the coast of California, in a well-known seismic region. The latter had its origin time $14 \mathrm{~h}$. $35.4 \mathrm{~m}$. G.M.T, and on a basis of reports from 18 seismographic stations the epicentre was calculated to be latitude $14.5^{\circ} \mathrm{N}$., longitude $94^{\circ} 0^{\circ} \mathrm{W}$. This is in the Pacific Ocean almost due west of Guatemala in Central America, also in a well-established seismic zone.

\section{University of London: Certificate in Natural History}

THE University of London has now published amended regulations (applicable for the duration of the present emergency) for its certificate of proficiency in natural history. The new scheme takes advantage of the fact that large numbers of urban teachers are now located in the country or at the seaside, and so presented with an opportunity of natural history study in the field which, under normal peace-time conditions, would have been impossible. The requirements embrace a directed course of private reading at home, attendance at a practical laboratory course of two weeks duration in the summer, an approved plan of field-work suited to the student's locality to be written up in the form of a substantial essay, and examination. Copies of the regulations and syllabus can be obtained from the University Extension Registrar, University of London, at Royal Holloway College, Englefield Green, Surrey. Several local education authorities are prepared to consider sympathetically applications for financial grants-in-aid from teachers in their areas who wish to study for the certificate.

\section{Occurrence of Larger Fungi in the Tropics}

A BRIEF note by E. J. H. Corner (Trans. Brit. Mycol. Soc., 24, 3 and 4; Dec. 1940) again directs attention to the interesting question of the occurrence of the larger fungi in the tropics. His experience in Malaya is in emphatic contrast to that of $\mathbf{G}$. B. Masefield (ibid., 24, 64-67 ; 1940), who had suggested that large fleshy fungi are scarce in number and variety 